
\title{
3 Research S Suare \\ POLIDON approach- a novel approach for mastoidectomy in COVID-19 pandemic.
}

Mostafa Kamal Arefin ( $\nabla$ arefin61dmc@gmail.com )

Dhaka Medical College Hospital

Md.Baha Uddin

ENT \& Head Neck Cancer Hospital \& Institute

Md. Zahidul Islam

Satkhira Medical College Hospital

Mohammad Shaharior Arafat

Dhaka Medical College Hospital

Md. Noor Kutubul Alam

Jashore Medical College

Debesh Chandra Talukder

Dhaka Medical College Hospital

Shaikh Nurul Fattah Rumi

Dhaka Medical College Hospital

Md. Nazmul Islam

Directorate General of Medical Education

Brig. General Dr. AKM Nasiruddin

Dhaka Medical College Hospital

Md. Abu Yusuf Fakir

Directorate General of Health Services

\section{Method Article}

Keywords: POLIDON, Mastoidectomy, COVID-19, Povidone lodine, Polythene

Posted Date: July 9th, 2020

DOI: https://doi.org/10.21203/rs.3.rs-40231/v1

License: (c) (i) This work is licensed under a Creative Commons Attribution 4.0 International License.

Read Full License 


\section{Abstract}

\section{Background}

WHO declared COVID-19 outbreak as pandemic in March, 2020, which was started from Wuhan of china. Mastoidectomy is an aerosol generating procedure. If a patient of COVID-19, either confirmed, suspected or asymptomatic career, requires mastoidectomy urgently, it's a critical issue for the health care professionals for the highly contagious nature of this novel corona virus. Here, some simple, but novel and very effective measures will be discussed for protection of all health care providers (HCPs). Polythene sheet and Povidone lodine are the change makers in this novel approach of mastoidectomy, mentioned in this article. So, we named the technique as 'POLIDON approach' of mastoidectomy.

Method/ Material

Placement of a transparent, sterile polythene sheet which acts as an interface between patient and surgeons and all other OR staffs is an important issue. Meanwhile, extended use of Povidone lodine (PVP-I) is recommended in different way.

Mouthwash for gargling and nasal application either by spray or nasal irrigation or drop will reduce viral load from nose and mouth of patient. HCPs should use PVP-I prophylactically also. Thus the chance of transmissibility of novel coronavirus is reduced

Meanwhile, Povidone lodine should be mixed with irrigating fluid to help in reduction of contamination by bone dust mixed with fluid, produced during surgery.

\section{Conclusion}

As mastoidectomy is an aerosol generating procedure, and novel coronavirus is highly contagious, so higher level of protection is required. A simple and cheap polythene sheet as barrier drape as well as rational and novel use of Povidone lodine, i.e. the proposed 'POLIDON' approach can significantly reduce the chance of corona virus transmission among the health care professionals working in the operation theatre.

\section{Background}

WHO declared COVID-19 outbreak as pandemic in March, 2020, which was started from Wuhan of china. During this pandemic, (every person or patient has chance of being infected with corona virus,) nobody is immune of being infected with coronavirus or being asymptomatic career of this 1 .

Mastoidectomy is an important surgical procedure in which all the accessible mastoid air cells are accenterated with an aim to make the ear safe 2, 3, 4. CSOM with extracranial and intracranial 
complications are indications of emergency or urgent mastoidectomy. The indications of urgent or emergency mastoidectomy are a bit changed recently 5,6. In the last few decades brain abscess due to CSOM was advocated and practised to be treated in two stage, at first incision and drainage of brain abscess, then 2-4 weeks later mastoid exploration. But, recently single stage urgent otological procedure is advocated (and it is without any delay) for minimizing mortality and morbidity. In a developing countrylike Bangladesh, lot of patients present to the hospitals at advanced stage usually with complications, like mastoiditis (not responsive to conservative treatment), facial palsy, labyrinthitis, extradural abscess, brain abscess, meningitis, lateral sinus thrombosis, otitic hydrocephalus which warrants urgent surgery.5,6,7. In our context, emergency mastoidectomy is not uncommon, especially in our centre, i.e. Dhaka Medical College Hospital, a tertiary level hospital 8.

Mastoidectomy is an aerosol generating procedure. If a patient of COVID-19, either confirmed, suspected or asymptomatic career, requires mastoidectomy for any of those indications, it's a critical and alarming issue for the health care professionals, including doctor, nurse, other OR (operating room) staff for the highly contagious nature of this virus 9 .

In current situation prior to any (routine) surgery report of RT-PCR test for coronavirus is mandatory. Negative results do not preclude SARS-CoV-2 infection and should not be used as the sole basis for patient management decisions. Negative results must be combined with clinical observations, patient history, and epidemiological information 10. In a developing country-like Bangladesh, patient presents to the hospitals at advanced stage usually with complications, like mastoiditis, facial palsy, labyrinthitis, extradural abscess, brain abscess, meningitis, lateral sinus thrombosis, otitic hydrocephalus 8,11.

RT-PCR test for detection of coronavirus is not available throughout the country, due to lack of laboratory facility, kit, technologist and other support. Due to partial or complete lockdown state mobility for the patient is also not easy rather very difficult. So confirmation of COVID-19 by RT-PCR test can't be done instantly everywhere. Prior to surgery it's recommended to do a CT scan of chest to find clue regarding COVID-19 12. But sometimes situation is unfavourable for doing it also. Few days or even hours are demarcating line between life and death or overall morbidity.

For this reason health care professionals should take maximum protections for their own safety within lots of limitation, seeming every patient as a COVID-19 patient.

Though the government, local authorities, personally all HCPs are trying to provide or collect adequate personal protective equipment (PPE) or other measures, throughout the world there is deficiency of it. In a resource constraint country, like us, we need to have cheap, affordable, easily available measures for protection.

Here, some simple, but novel and very effective measures will be discussed for protection of all health care providers (HCPs) in this aerosol generating procedure. Polythene and Povidone lodine are the change makers in this novel technique of mastoidectomy, mentioned in this article. So, we named the technique as 'POLIDON technique' of mastoidectomy. 


\section{Method / Material}

In our setting, placement of a transparent, sterile polythene sheet which acts as an interface between patient and surgeons and all other OR staffs is the most important issue. Meanwhile, extended use of Povidone lodine (PVP-I) is recommended in different way.

Mouthwash for gargling and nasal application either by spray or nasal irrigation or drop will reduce viral load from nose and mouth of patient. HCPs should use PVP-I prophylactically also. Thus the chance of transmissibility of novel coronavirus is reduced $13,14,15$.

Meanwhile, Povidone lodine should be mixed with irrigating fluid to help in reduction of contamination by bone dust mixed with fluid, produced during surgery.

This technique was innovated by the corresponding author and applied in Dhaka Medical College Hospital and Taqwa General Hospital (, a private hospital) in three emergency/ urgent mastoid surgeries.

\section{Povidone lodine}

In 1955 Povidone-iodine (iodine with water-soluble polymer polyvinylpyrrolidone, PVP-I) was invented. The active moiety, non PVP-bound (free) iodine is released into solution from the PVP-I complex. PVP delivers the free iodine to target cell membranes. Free iodine, that mediates the basic mechanism of action (oxidation of amino acids and nucleic acids in biological structures), which is difficult to counteract. This basic mechanism of action leads to strong microbicidal activity expressed by multiple modes of action that include the disruption of microbial metabolic pathways, as well as destabilisation of the structural components of cell membranes, causing irreversible damage to the pathogen. Consumed free iodine is then replaced by PVP-bound iodine. The concentration of free iodine is the determining factor of the microbicidal action of PVP-I. In a study investigating the virucidal activity of different disinfectants, Electron micrographic study revealed that, exposure of iodine led to destruction of nucleoproteins of viral particle-which is the main mechanism of action 16,17 . However, disruption of surface proteins essential for the spread of enveloped viruses has also been noted 16, 18. Furthermore, lodine is a scavanger of free radical oxygen species, contributing to anti-inflammatory properties 16,19 . This interaction ultimately results in microbial death 16-26.

\section{Virucidal activity of PVP-I}

Povidone-iodine has been reported as having the highest virucidal activity profile among several antiseptics such as Chlorhexidine (CHG), Benzalkonium chloride (BAC), BEC and Alkyldiaminoethylglycine hydrochloride (AEG) 16, 20.

PVP-I has been shown to be active in vitro against the coronaviruses that have caused epidemics in the last two decades, namely SARS-CoV causing the severe acute respiratory syndrome (SARS) epidemic of 2002-3 and MERS-CoV the agent responsible for causing the Middle East respiratory syndrome (MERS) 
epidemic of 2012-13. SARS-CoV-2 is highly homologous with SARS-CoV, and as such it is considered a close relative of SARS-CoV1015. In his study Egger et al suggests that, upto $0.23 \%$ concentration of PVP-I is virucidal 17, 18. Kariwa showed that treatment in vitro of SARS-CoV with various preparations of PVP-I for 2 minutes was enough to reduce viral activity to undetectable levels14. The lowest concentration used was $0.23 \%$, found in an over the counter throat spray 18 . Recent studies conclude that SARS-CoV-2 should behave similarly 21 16-26.

\section{Plastic/Polythene:}

Modern healthcare would not be possible without the use of plastic materials.

Polythene is one type of it, which is popular for its greater flexibility, comfort and mobility. Polythene, with its exceptional barrier properties, light weight, low cost, durability, biocompatibility and transparency, is ideal for medical applications.

Today's most innovative medical procedures are dependent on plastics

We designed a technique to use it like ototent (please see figure) 27.

\section{Proposed Steps of Mastoidectomy in COVID-19 pandemic}

1. Consent- written informed consent is mandatory.

\section{Preparation of patient}

- Prior to surgery, patient is to gargle with $10-15 \mathrm{ml} \mathrm{PVP-I} 1 \%$ (undiluted) or $30 \mathrm{ml} 0.5 \%$ (diluted with same amount of water) mouthwash solution

- Nasal irrigation with PVP-I ( $0.5 \%)$ is to be given, in case of difficulty or inconvenience of patient PVP-I nasal spray or drop should be applied.

\section{Preparation of members of surgical team}

- Sterile surgical gown should be put over impermeable gown or protective apron.

- FFP3 or FFP2 or N95 mask or PAPR on face

- Eye protective goggles

- Hood cap is preferable than simple cap forehead protection.

- Double gloves is preferable.

- All health care professionals are proposed to use PVP-I for gargling and applying in nose in same manner as proposed for patient for protection as adjunct to PPE before and/ or after mastoidectomy.

- During induction of anaesthesia and intubation full surgical team, except anaesthetist and one or two staff, necessary for this step, is to stay outside the OT. 
5 minutes later full team is to enter into the $0 \mathrm{~T}$.

4. Positioning of the patient.

5. Skin should be prepared with PVP-I 10\% solution.

6. PVP-I is to be mixed with irrigating fluid in atleast 1:10, i.e. $100 \mathrm{ml}$ in 1 litre of normal saline.

7. Draping is to be done properly.

8. Infiltration of local anaesthesia with Lignocaine with adrenaline.

9. A postauricular incision (usually) is to be made.

10. Skin, subcutaneous tissues are to be

11. Temporalis fascia is to be harvested.

12. Posteriorly or superiorly based flaps are to be made.

13. Another incision in external auditory canal 1 to 4 o'clock (traditionally 6 to 12 o'clock) position is to be made.

14. Mastoid retractors are to be fixed in position so that whole tympanic membrane (TM) could be visualized.

15. Margin of perforation is to be freshened.

16. Tympanomeatal flap is to be elevated.

17. Prior to start of drilling one or two additional, transparent, sterile polyethene sheet is to place and fix over the operative field, like an extra drapping sheet and a tent, where the apex is formed at microscope objective eye piece. This step can be performed prior to incision also.

Hands of surgeons and all necessary instruments kept inside the polythene sheet, the tent. Surgeons hands are to be fixed with the polythene sheet with adhesive tape.

Some ports in polythene sheet like microscope drape, for entry of surgeon and assistant's hand can be made.

18. Mastoid drilling is to be started targeting the triangle of attack.

19. Drilling is to be continued for complete disease removal and completion of surgery

20. Cartilage or TORP or PORP is to be used for ossiculoplasty or other type of reconstruction.

21 . Temporalis fascia is to be placed properly.

22. Wound is to be closed in layers after proper haemostasis.

23. Ototent made by polythene is to be removed.

24. Mastoid bandage is to be applied.

25. Anesthesiologist is to start the reversal process.

During extubation full surgical team, like before, is to stay outside OT again. Five minutes after extubation they should enter inside OT. 
26. Proper doffing is to be done after the operative session $2,3,4$

\section{Preparation of application of Povidone lodine or PVP-I prior to surgery:}

A. For gargling and mouthwash :

i. For fully conscious patient-

PVP-I $1 \%$ solution (undiluted) $10 \mathrm{ml}$ for $30 \mathrm{sec}$ to 1 minute or $0.5 \%$ solution (diluted by mixing same amount of water, i.e. $10 \mathrm{ml}$ PVP-I with $10 \mathrm{ml}$ water ) $20 \mathrm{ml}$ for 1-2 minutes.

ii) For patient with altered consciousness - A sponge swab or similar is soaked in 2-5 $\mathrm{ml}$ of $1 \%$ PV P-I and this is carefully wiped around all oral mucosal surface

A. For nasal application:

Nasal spray: 2-3 puff in each nostril with a standard atomizing devise with $0.5 \%$ solution of PVP-I or Nasal irrigation: Irrigate or wash through both nostril with $200-300 \mathrm{ml}(100-150 \mathrm{ml}$ in each nostril) of $0.5 \%$ PVP-I solution or

Nasal drop: If nasal spray or irrigation facility is not available apply nasal drop 3-4 drops in each nostril $13,14,28$.

\section{Preparation of PVP-I mixed irrigating fluid:}

$100 \mathrm{ml}$ of PVP-I $10 \%$ solution is to be mixed with $900 \mathrm{ml}$ of Normal saline to make a PVP-I 1\% solution. 50 $\mathrm{ml}$ of PVP-I 10\% solution can be mixed with $950 \mathrm{ml}$ of Normal saline also.

Polythene: Simple, transparent polythene.

The plastic / polythene sheet allows good mobility of the hands of the surgeon's. In spite of being transparent or translucent, there may have some degree of glare.

Several modifications can be done. Our focus is on the simplest method. Any positive modification is appreciable. We designed a technique to use it like ototent (please see figure) 27.

Microscope drape is an alternative, relatively expensive, but not available everywhere, especially in developing or any resource constraint country 9, 22.

\section{Special considerations:}

- Number of health care professionals in the OT should be minimum. In an ear surgical procedure, only one or two surgeons is/are needed to be in the OR and all observers should be excluded. This is important to reduce potential exposures, but also to limit use of PPE (mainly N95 masks). 
- Experienced and skilled surgical team is must.

- If facility and time allows mastoidectomy should be done under general anaesthesia in a negative pressure room.

- Electrocauterization by monopolar diathermy should be avoided, otherwise minimized.

- For educators, making a video recording of the surgery is to be suggested to share with trainees, if possible, rather trained them under direct guidance 24 .

\section{Discussion}

In the current COVID-19 situation, healthcare professionals are prone to be infected with SARS-CoV-2/ novel corona virus more than any other people. Absentism of HCPs and spread to their family members are big threats on healthcare system at this crisis period 30. Nosocomial transmission of SARS-CoV- 2 is common in ENT, dental, ICU or critical care unit, as aerosol generating procedures like- ventilation, intubation, suction, tracheostomy commonly performed here and the bioaersol may represent more of a potential inoculum than by community transmission 31 .

Mastoidectomy is an aerosol generating procedure 29.

Though it is not confirmed whether the respiratory mucosa, lining the middle ear and mastoid air cells system is involved by COVID19 or not-but it seems likely that they are. As the rest of the /airway is involved, and the nose and nasopharynx are intensely involved, it seems probable that the lining of the eustachian tube, middle ear, and mastoid air cell system are all contaminated. Several articles verify the presence of respiratory virus in the middle ear during acute illnesses. During upper respiratory tract infection coronavirus (not novel corona virus) in the middle ear were specifically documented in some other studies. These viruses have affinity for respiratory mucosa and may involve the otic structures either via direct mucosal spread or viremia. Drilling through the mastoid creates droplets and aerosols in significant clouds which, if virus is present, could risk infecting everyone in the operating room environment. Precaution and attention is very important, as contaminated mists harbour viable virus for few hours, especially in enclosed spaces. So, mastoidectomy should be regarded as a procedure of heightened risk 29, 32,33,34,35,36

It has been reported that, following transnasal endoscopic surgery, where powered instruments (including drills) were used, that create plumes of droplets- infected OR staffs.

Ideally, test for COVID-19 is recommended preoperatively for any ear surgery and, if negative, proceed with surgery using standard PPE.Though COVID-19 can't be ruled out entirely early infections with undetectable viral load or even false negative testing. If positive, surgery should be delayed until the patient has cleared the disease. Hence the pre-procedure test as indicated in their view because it would affect management 29. 
In another study,Mastoidectomy with a high-speed drill was simulated using fresh-frozen cadaveric heads with fluorescein solution injected into the mastoid air cells. Cadaveric head specimens were drilled for one-minute in test conditions with and without a microscope. A barrier drape was fashioned from a commercially available drape (the OtoTent). Dispersed particulate matter was quantified in segments of an octagonal test grid measuring $60 \mathrm{~cm}$ in radius.

Drilling without a microscope dispersed fluorescent particles 360 degrees, with the areas of highest density in quadrants near the surgeon and close to the surgical site. Using a microscope or varying irrigation rates did not significantly reduce particle density or percent surface area with particulate. Using the OtoTent significantly reduced particle density and percent surface area with particulate across the segments of the test grid beyond $30 \mathrm{~cm}$ (which marked the boundary of the OtoTent) compared with the microscope only and no microscope test conditions 37 . Right now it is established that a barrier drape is essential for safety.

Viruses often bind to receptor proteins on the surface of cells in order to enter in human cells, for example, novel coronavirus binds to ACE2 receptor 38. ACE2 could be expressed in the oral cavity. Moreover, among different oral sites, ACE2 expression was higher in tongue than buccal and gingival tissues 39. In COVID-19 high viral load is found in saliva (when the saliva of patients was analysed at the time of admission to hospital) 40.

Uniquely in Japan, gargling is generally accepted and strongly recommended as a preventive measure for URTI, in addition to hand washing and the wearing of masks 41 . Recent study reveals that the nasopharynx appears to have a higher viral load than that found in the oropharynx 42 . So that, nasal administration of PVP-I is as important as gargling with PVP-I mouthwash. Again, PVP-I is the time tested and trusted antiseptic agent, having best possible (99.99\%) virucidal effect (even against SARS-CoV2) with only of its $0.23 \%$ concentration $22-25$.

Povidone lodine is safe for gargling as mouthwash, for inhalation or instillation as nasal spray, drop or vapour. PVP-I Nasal Spray directly attacks viruses by trapping and disabling them in the nasal cavity. The disabled viruses are then expelled with the product after blowing the nose13, 14,15,28.

By destroying/eliminating the culprit virus from its route of entry, risk of transmission of COVID-19 from patient to health care professionals will be reduced in significant amount as well as viral load of COVID19 infected patients will be minimized. So Patient as well as health care professionals should use Povidone lodine accordingly.

In our study, to protect HCPs of surgical team from being infected with respiratory droplet and aerosol, simplest and cheapest barrier drape is designed. Polythene is a suitable option in a resource constraint country like Bangladesh. Polythene is popular for its greater flexibility, comfort and mobility. Polythene, with its exceptional barrier properties, light weight, low cost, durability, biocompatibility and transparency, is ideal for medical applications. 
It can be sterilized by Glutaraldehyde, Formaldehyde or Ethylene Oxide easily. Polythene is available everywhere, even in rural place 43.

In this article, we added Polythene barrier and Povidone lodine for protection for transmission of novel corona virus in addition with existing technique of mastoidectomy. Simple addition will dramatically change the fear of doing this emergency lifesaving procedure and overall outcome.

\section{Conclusion}

As mastoidectomy is an aerosol generating procedure, and novel coronavirus is highly contagious, so higher level of protection is required. A simple and cheap polythene sheet as barrier drape as well as rational and novel use of Povidone lodine, i.e. the proposed 'POLIDON' approach can significantly reduce the chance of corona virus transmission among the health care professionals working in the operation theatre.

\section{Declarations}

\section{Conflict of interest}

All authors declared, there is no conflict of interest.

\section{Contributions}

Corresponding author is Arefin MK. He generated the idea of the technique, which was appreciated and accepted by all the authors. Arefin MK prepared the manuscript and submitted. All other authors read, revised and participated in coordination of this article.

\section{References}

1. Novel Coronavirus Pneumonia Emergency Response Epidemiology Team. [The epidemiological characteristics of an outbreak of 2019 novel coronavirus diseases (COVID19) in China]. Zhonghualiuxingbingxuezazhi = Zhonghualiuxingbingxuezazhi 2020; 41:145-51

2. Bingham BJG, Hawthorne MR. Mastoid surgery. In: Synopsis of operative surgery, Butterworth Heinemann, Oxford.1992; 105-123.

3. Dhingra PL. Mastoid surgery.In: Disease s of Ear, Nose and Throat. 6 th ed. New Delhi, Elsevier.2010; 409-412.

4. Ludman H. Reconstruction of the middle ear- In Booth JJB, editor Scott- Brown;s Otolaryngology. 6 th ed.Vol-3. London: Butterworth- Heinman,1997:3/11/ 1-30

5. Browning GG et al. Chronic otitis media. In: Gleeson Met al. Scott Brown's Otorhinolaryngology, Head \& Neck Surgery 7 th ed. London, Hodder Arnold. 2008:3396-3445. 
6. Browning GG et al. Chronic otitis media. In: Scott Brown's Otorhinolaryngology, Head \& Neck Surgery 8 th ed. London, Hodder Arnold. 2018:977-1019

7. Duncan Bowyer et al. Complications of otitis media. In: Logan Turner;s Diseases of the nose, throat and ear , Head and neck surgery 11 th ed. Newyork, Taylor \& Francis.2016; 421-431.

8. Arefin MK, Khan AFM, Fakir MAY.Outcome of canal wall down mastoidectomy: A prospective clinical study. Beacon Med.J.2018; Vol-1(1);11

9. Heller W, Mitchell T, Thomas S. Mastoidectomy in the COVID era - the 2 microscope drape method to reduce aerosolization.

https://www.entuk.org/sites/default/files/Mastoidectomy\%20in\%20the\%20COVID\%20Era \%20\%E2\%80\%93\%20The\%202.pdf. Accessed April 20, 2020

10. LabCorp COVID-19 RT-PCR test EUA Summary 1 -ACCELERATED EMERGENCY USE AUTHORIZATION (EUA) SUMMARY COVID-19 RT-PCR TEST (LABORATORY CORPORATION OF AMERICA)

11. Hossain MM, Kundu SC, Hoque MR, Shamsuzzaman AKM. Extracranial complications of chronic suppurative otitis media. A study on 100 cases. Mymensingh Medical journal Fakir MAY, Hanif A, Ahmed KU. Intracranial complications of CSOM- A study of 40 cases. Bangladesh Journal of Otorhinolaryngology.

12. Shi, X. Han, N. Jiang, Y. Cao, O. Alwalid, J. Gu, et al. Radiological findings from 81 patients with COVID-19 pneumonia in Wuhan, China: a descriptive study Lancet Infect Dis (2020), 10.1016/S14733099(20)30086-4

13. Arefin MK, Islam MZ, Shawrave MSA et al. The role of Povidone lodine mouthwash \& nasal spray or drop or inhalation for protection of health care professionals as well as patients and reduction of cross infection during current COVID-19 pandemic situation. IJSR 2020; 9(4):

14. Bayley JK, Challacombe S, Sunkaraneni VS, Combes J. The use of Povidone iodine nasal spray and mouthwash during COVID-19 pandmic may protect healthcare workers and reduce cross infection. Social Science Research Network (Draft version, waiting for journal acceptance and full peer review.)

15. Mady LJ, Kubik MW: Consideration of povidone-iodine as a public health intervention for COVID-19: Utilization as "Personal Protective Equipment" for frontline providers exposed in high-risk head and neck and skull base oncology care. Oral Oncol.2020;105

16. Berkelman RL, Holland BW, Anderson RL. Increased bactericidal activity of dilute preparations of povidoneiodine solutions. Journal of clinical microbiology 1982; 15: 635-9.

17. KanagalingamJ, FelicianoR, HahJH, LabibH, LeTA, LinJC. Practical use of povidone iodine antiseptic in the maintenance of oral health and in the prevention and treatment of Common oropharyngeal infections. International Journal of Clinical Practice 2015.DOI: 10.1111/ijcp.12707.

18. Schreir H, Erdos G, Remer K, et al. Molecular effects of Povidone lodine on relevant microorganisms: an electron microscopic and biochemical study. Dermatology 1997;195:111-7.

19. Sriwilaijaroen $\mathrm{N}$, Wilairat $\mathrm{P}$, Hiramatsu $\mathrm{H}$ et al. Mechanisms of the action of povidone-iodine against human and avian influenza A viruses: its effects on hemagglutination and sialidase activities. Virol J 2009; 6: 124. 
20. Beukelman CJ, van den Berg AJ, Hoekstra MJ, Uhl R, Reimer K, Mueller S. Anti-inflammatory properties of a liposomal hydrogel with povidone-iodine (Repithel) for wound healing in vitro. Burns 2008; 34: 845-55.

21. Kawana T, Kitamura T, Nakagomi 0 et al. Inactivation of human viruses by povidone-iodine in comparison with other antiseptics. Dermatology 1997; 195: 29-35.

22. Wu C, Liu Y, Yang Y, et al. Analysis of therapeutic targets for SARS-CoV-2 and discovery of potential drugs by computational methods. ActaPharmaceuticaSinica B

23. Eggers M, Eickmann M, Zorn J. Rapid and Effective Virucidal Activity of Povidone-lodine Products Against Middle East Respiratory Syndrome Coronavirus (MERS-CoV) and Modified Vaccinia Virus Ankara (MVA). Infectious diseases and therapy 2015; 4: 491- 501.

24. Eggers M. Infectious Disease Management and Control with Povidone lodine. Infectious diseases and therapy 2019; 8: 581-93.

25. Eggers M, Koburger-Janssen T, Eickmann M, Zorn J. In Vitro Bactericidal and Virucidal Efficacy of Povidonelodine Gargle/Mouthwash Against Respiratory and Oral Tract Pathogens. Infectious diseases and therapy 2018; 7: 249-59.

26. Kariwa H, Fujii N, Takashima I. Inactivation of SARS coronavirus by means of povidoneiodine, physical conditions and chemical reagents. Dermatology (Basel, Switzerland) 2006; 212 Suppl: 119-

27. The many uses of plastic materials in medicine. Craftech industries. Inc.

28. Mubarak Muhamed Khana, Sapna Ramkrishna Paraba, Mandar Paranjapeb. Repurposing $0.5 \%$ povidone iodine solution in otorhinolaryngology practice in Covid 19 pandemic

29. Carron JD, Buck LS. A Simple Technique for Droplet Control During Mastoid Surgery. JAMA Otolaryngol Head Neck Surg.2020 Apr 28 : e201064.

30. Pitkäranta A, Jero J, Arruda E, Virolainen A, Hayden FG. Polymerase chain reaction-based detection of rhinovirus, respiratory syncytial virus, and coronavirus in otitis media with effusion. J Pediatr. 1998 Sep;133(3):390-4.

31. Pitkäranta A, Virolainen A, Jero J, Arruda E, Hayden FG. Detection of rhinovirus, respiratory syncytial virus, and coronavirus infections in acute otitis media by reverse transcriptase polymerase chain reaction. Pediatrics. 1998 Aug;102(2 Pt 1):291-5.

32. Wiertsema SP, Chidlow GR, Kirkham LA, Corscadden KJ, Mowe EN, Vijayasekaran S, Coates HL, Harnett GB, Richmond PC. High detection rates of nucleic acids of a wide range of respiratory viruses in the nasopharynx and the middle ear of children with a history of recurrent acute otitis media. J Med Virol. 2011 Nov;83(11):2008-17. doi: 10.1002/jmv.22221.

33. Nokso-Koivisto J, Räty R, Blomqvist S, Kleemola M, Syrjänen R, Pitkäranta A, Kilpi T, Hovi T. Presence of specific viruses in the middle ear fluids and respiratory secretions of young children with acute otitis media. J Med Virol. 2004 Feb;72(2):241-8.

34. Heikkinen T, Thint $M$, Chonmaitree T. Prevalence of various respiratory viruses in the middle ear during acute otitis media. N Engl J Med. 1999;340(4):260-264.

doi:10.1056/NEJM199901283400402.

Page $12 / 18$ 
35. Norris BK, Goodier AP, Eby TL. Assessment of Air Quality During Mastoidectomy. Otolaryngol Head Neck Surg. 2011;144(3):408-411. doi:10.1177/0194599810394967.

36. Wang D, Hu B, Hu C, et al. Clinical Characteristics of 138 Hospitalized Patients With 2019 Novel Coronavirus-Infected Pneumonia in Wuhan, China. JAMA: the journal of the American Medical Association 2020; 323: 1061-9.

37. Xu H, Zhong L, Deng $\mathrm{J} t$ al. High expression of ACE2 receptor of 2019- $\mathrm{n}$ CoV on the epithelial cells of oral mucosa. Int J Oral S. 2020; 12:8

38. To KK-W, Tsang OT-Y, Chik-Yan Yip C, et al. Consistent detection of 2019 novel coronavirus in saliva. Clinical infectious diseases: an official publication of the Infectious Diseases Society of America 2020; 361: 1319.

39. Sakai M, Shimbo T, Omata K, Takahashi Y, et al. Cost - effectiveness of gargling for the prevention of upper respiratory tract infections. BMC Health Services Research 2008; 8:258

40. Zou L, Ruan F, Huang M, et al. SARS-CoV-2 Viral Load in Upper Respiratory Specimens of Infected Patients. The New England journal of medicine 2020. DOI:10.1056/NEJMc2001737.35

41. Levinson W, Jawetz E. Sterilization \& Disinfection. In: Medical microbiology \& immunology, Examination \& board review.7 th edition. Newyork, Lange Medical Books/ Mcgraw- Hill, 2005: 84-

\section{Figures}




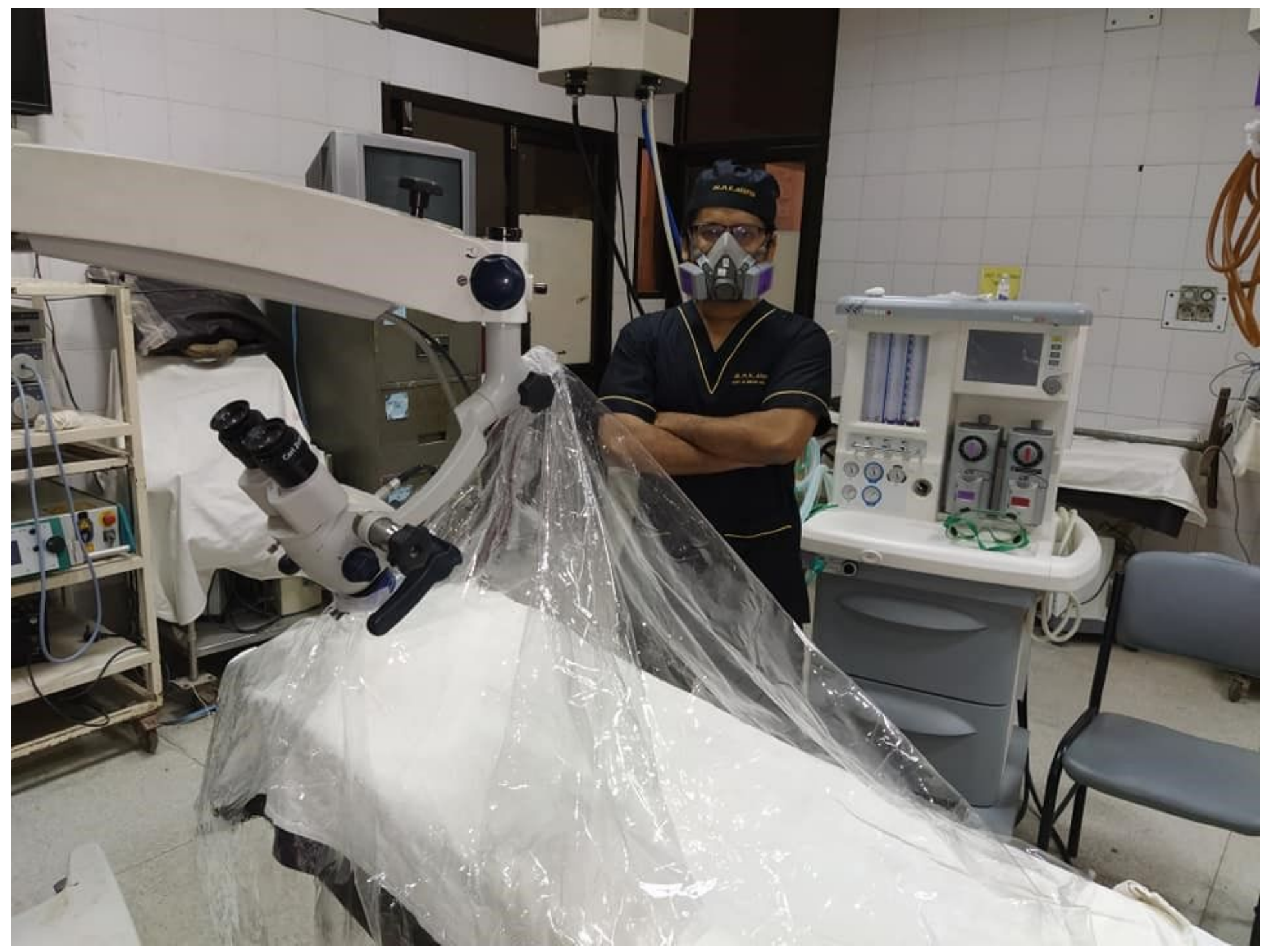

Figure 1

Ototent made by polythene sheet (the person in photo is Arefin MK, the corresponding author) 


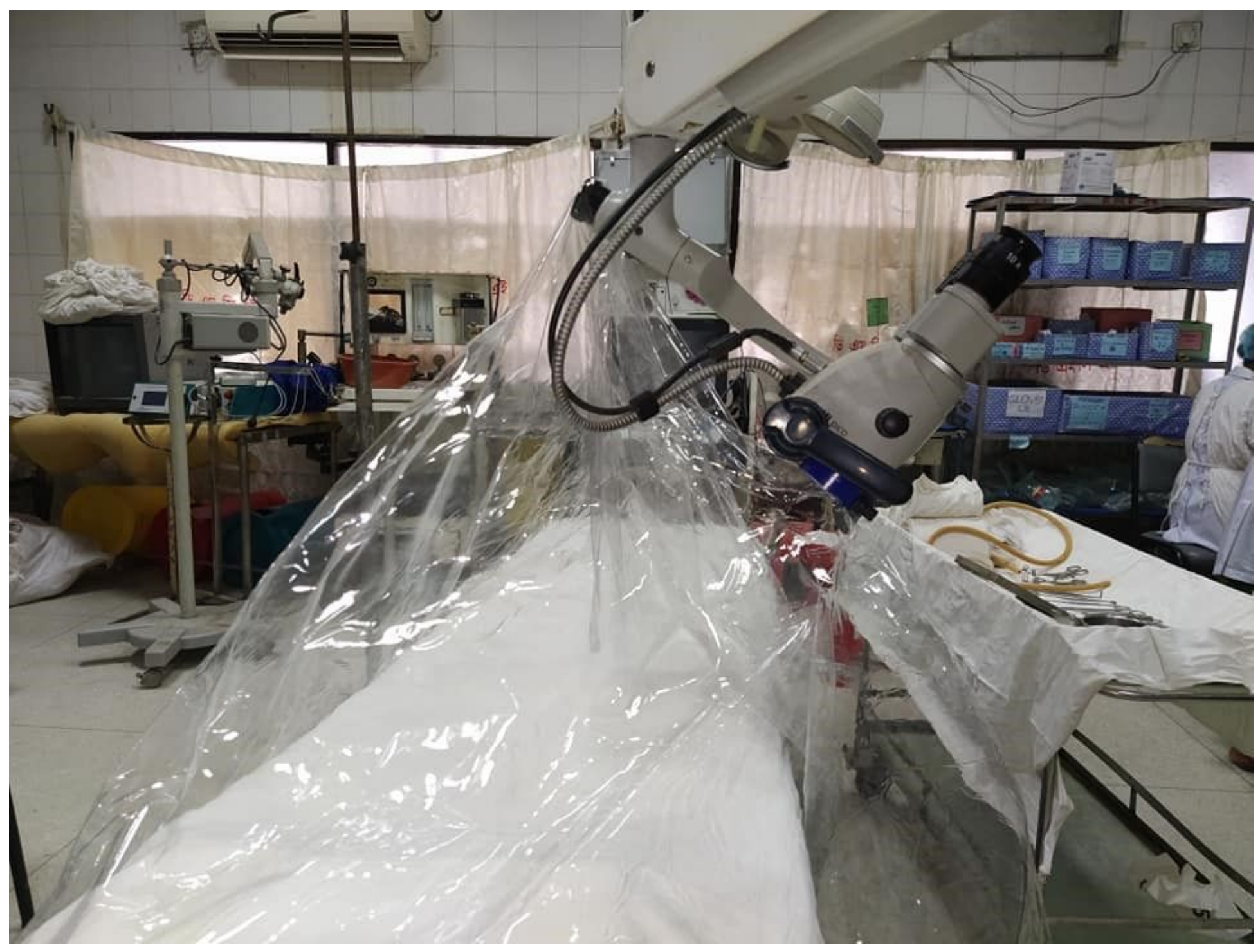

Figure 2

Polythene is fixed with Objective Lens and another point by creating hole in this polythene sheet and fixing it with micropore 


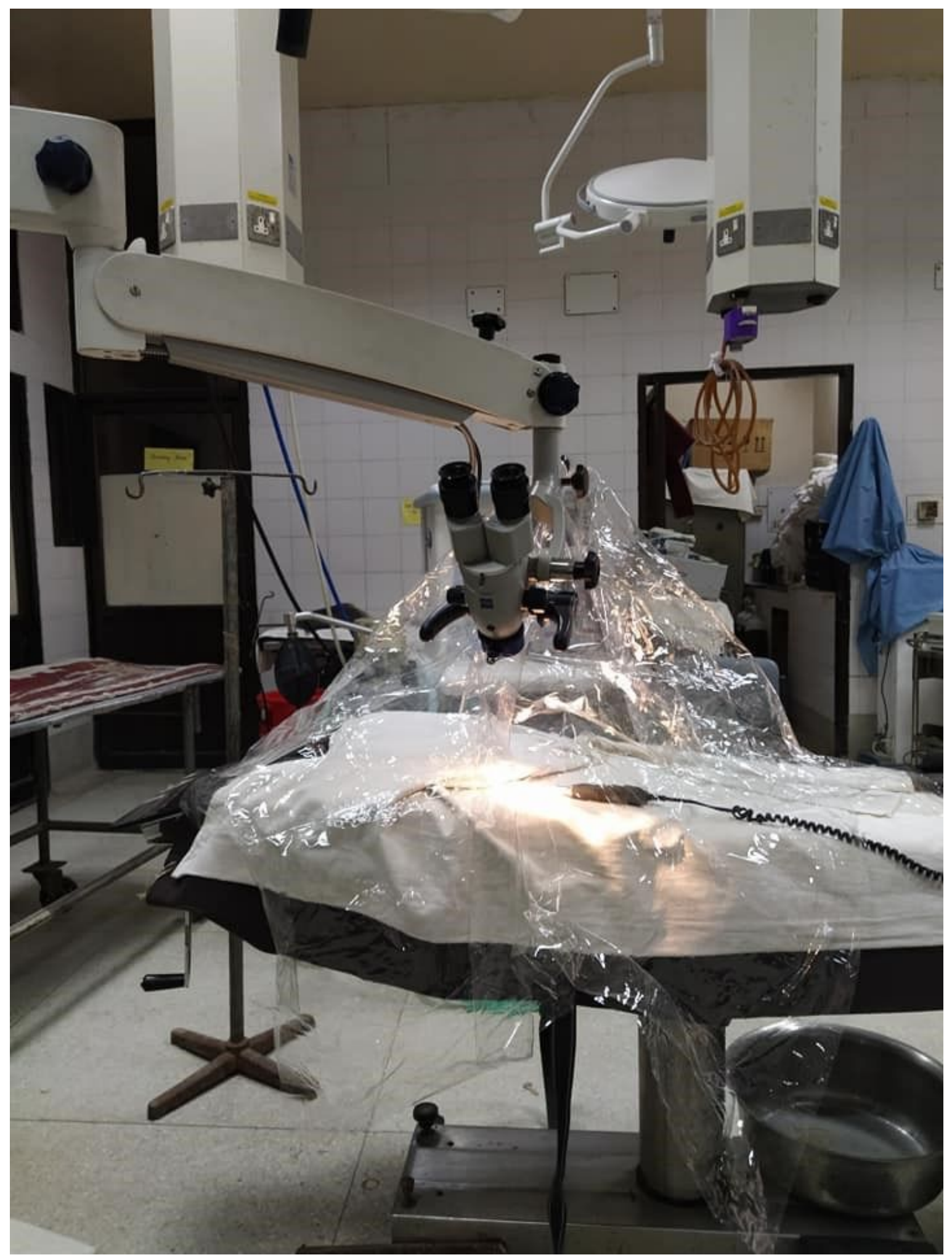

Figure 3

Ototent made by polythene 


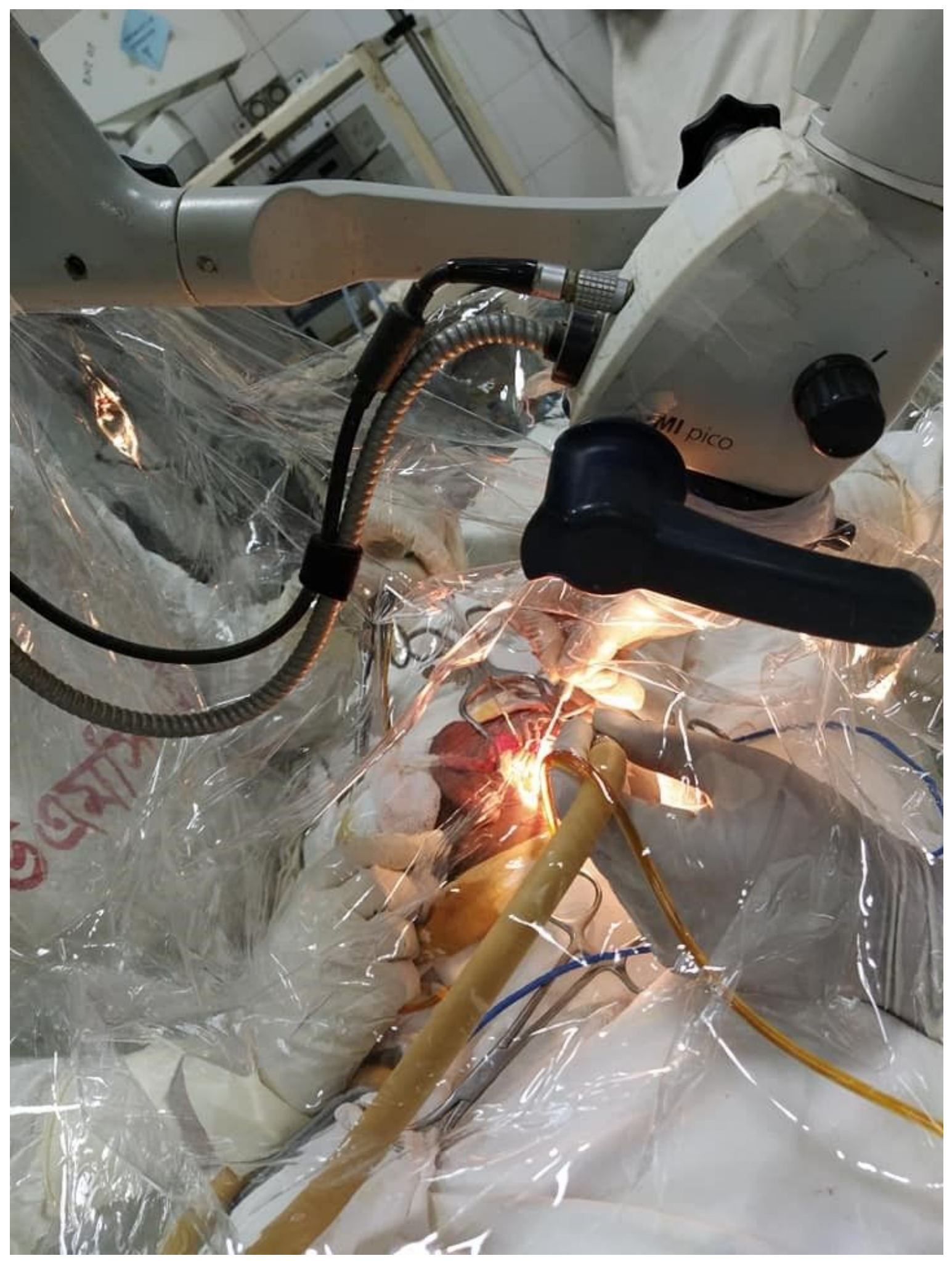

Figure 4

Hands of surgeon and assistant, sucker, diathermy wire and irrigating channel (containing PVP-I mixed fluid) are seen inside the polythene tent. 


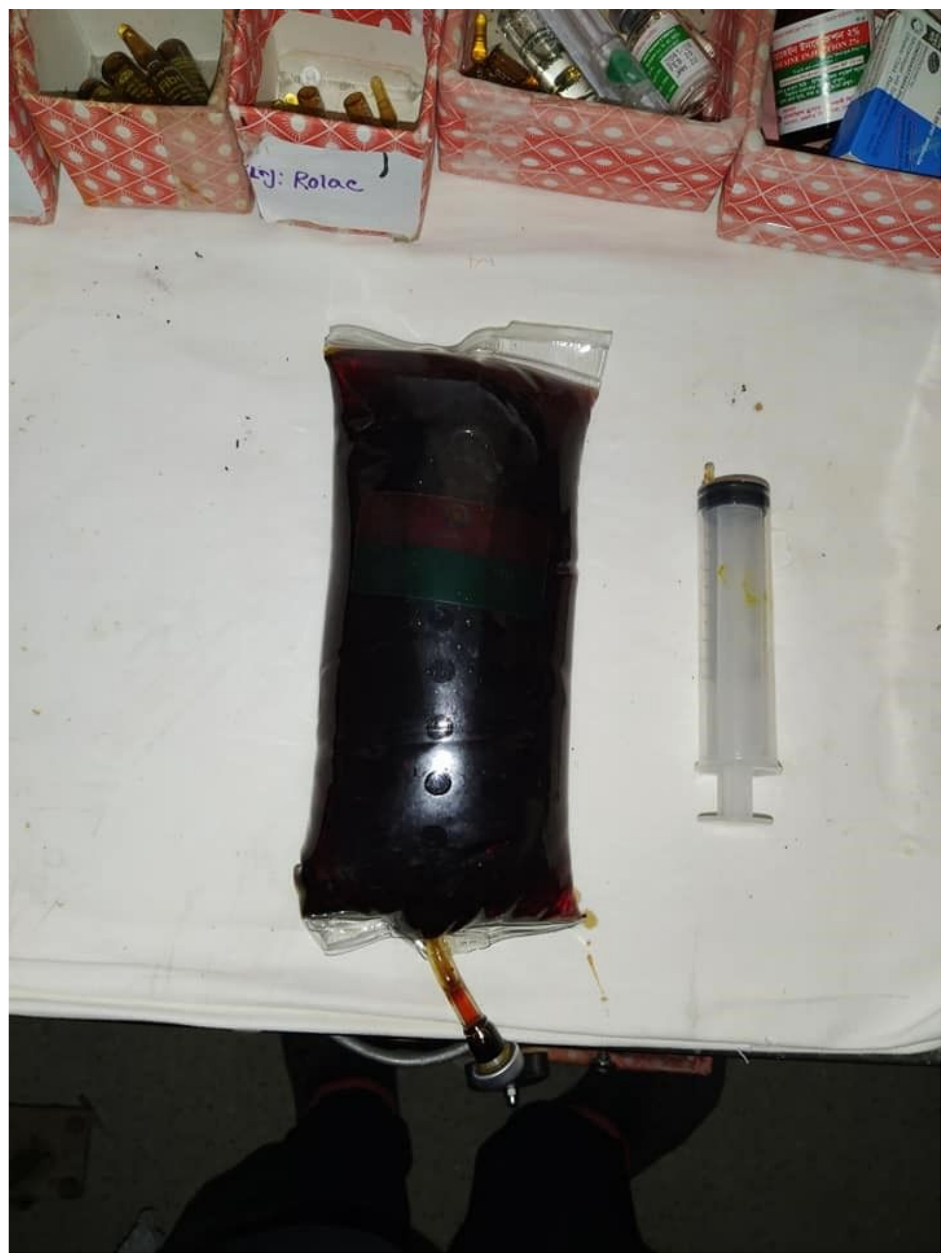

Figure 5

Irrigating fluid mixed with Povidone lodine Solution 